\title{
Forest inventory and aboveground biomass estimation with terrestrial LiDAR in the tropical forest of Malaysia
}

\begin{abstract}
An accurate forest inventory is crucial for forest monitoring and quantifying forest aboveground biomass (AGB). This study aimed to investigate the feasibility of Terrestrial Laser Scanning (TLS) in forest inventory and AGB estimation in the tropical forest of Malaysia. Individual trees were detected using manual and automatic detection methods. An average tree detection rate of $99.55 \%$ and $93.75 \%$ were achieved using the manual and automatic detection method respectively. The accuracy of the diameter at breast height $(\mathrm{DBH})$ of trees measured from TLS was validated using field $\mathrm{DBH}$ as reference. A root means square error (RMSE) of $1.37 \mathrm{~cm}(6.60 \%)$ and $2.36 \mathrm{~cm}$ (11.47\%), respectively, were obtained for manually and automatically measured TLS DBH. Similarly, TLS based tree height was validated using Airborne Laser Scanner (ALS) height as a reference and resulted in RMSE of $1.74 \mathrm{~m}(9.30 \%)$ and $3.17 \mathrm{~m}(17.40 \%)$ with manual and automatic method respectively. Finally, AGB was calculated using the variables derived from the TLS data. Results show an R2 value of 0.98 and RMSE of $0.08 \mathrm{Mg}$. The results of this study confirmed that TLS as a nondestructive approach can provide a very good estimation of forest attributes and AGB in the dense tropical forest conditions.
\end{abstract}

